\title{
Late presentation of capsule endoscope aspiration with successful extraction by flexible bronchoscopy utilizing a snare wire loop
}

Table 1 Demographic and clinical data of the patients with well-documented aspiration of a capsule endoscope.

\begin{tabular}{|c|c|}
\hline Age, mean, years & 79 \\
\hline Male/Female, n & $15 / 1$ \\
\hline Total number & 16 \\
\hline $\begin{array}{l}\text { Co-morbid risk factors } \\
\text { for aspiration, } \mathrm{n}\end{array}$ & 5 \\
\hline Dysphagia, n & 3 \\
\hline \multicolumn{2}{|l|}{ Symptoms/signs, $\mathrm{n}$} \\
\hline Cough & 12 \\
\hline Shortness of breath & 2 \\
\hline Throat pain & 1 \\
\hline Tachypnea & 1 \\
\hline Gagging & 1 \\
\hline Wheeze & 1 \\
\hline Asymptomatic & 2 \\
\hline \multicolumn{2}{|l|}{ Length of aspiration, $\mathrm{n}$} \\
\hline$\leq 5$ minutes & 7 \\
\hline$<24$ hours & 4 \\
\hline$>24$ hours & 2 \\
\hline Not provided & 3 \\
\hline \multicolumn{2}{|l|}{ Method of diagnosis, $n$} \\
\hline Recording download & 12 \\
\hline Radiographs & 4 \\
\hline Spontaneously coughed out, $\mathrm{n}$ & 9 \\
\hline $\begin{array}{l}\text { Removed by flexible fiberoptic } \\
\text { bronchoscopy, n }\end{array}$ & 5 \\
\hline Removed by rigid bronchoscope, $n$ & 2 \\
\hline
\end{tabular}

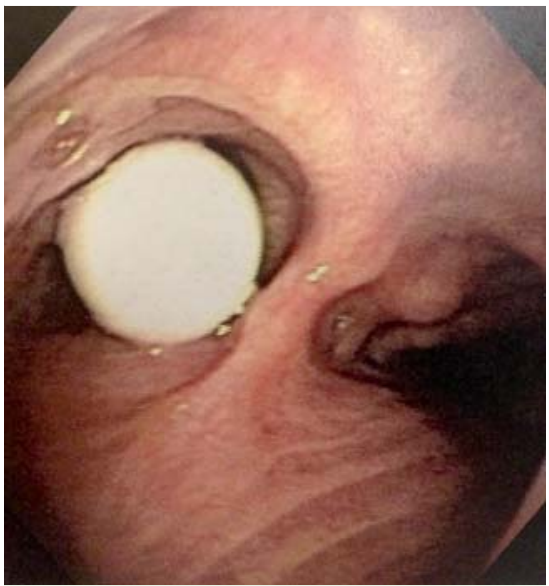

Fig. 2 The capsule endoscope was identified in the left main stem bronchus by fiberoptic bronchoscopy.

Capsule endoscopy is a commonly employed technique to examine patients for gastrointestinal pathology. Pulmonary aspiration of a capsule endoscope is a rare complication of this procedure. There have been 15 well-described instances of

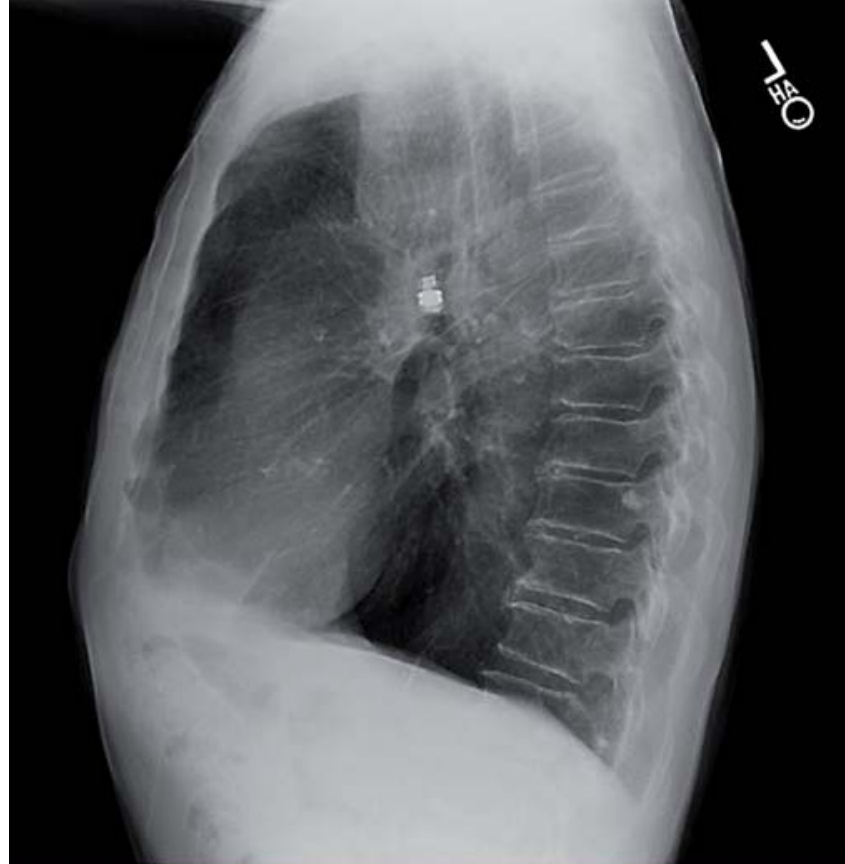

Fig. 1 Chest radiograph demonstrating the capsule endoscope in the left main bronchus.

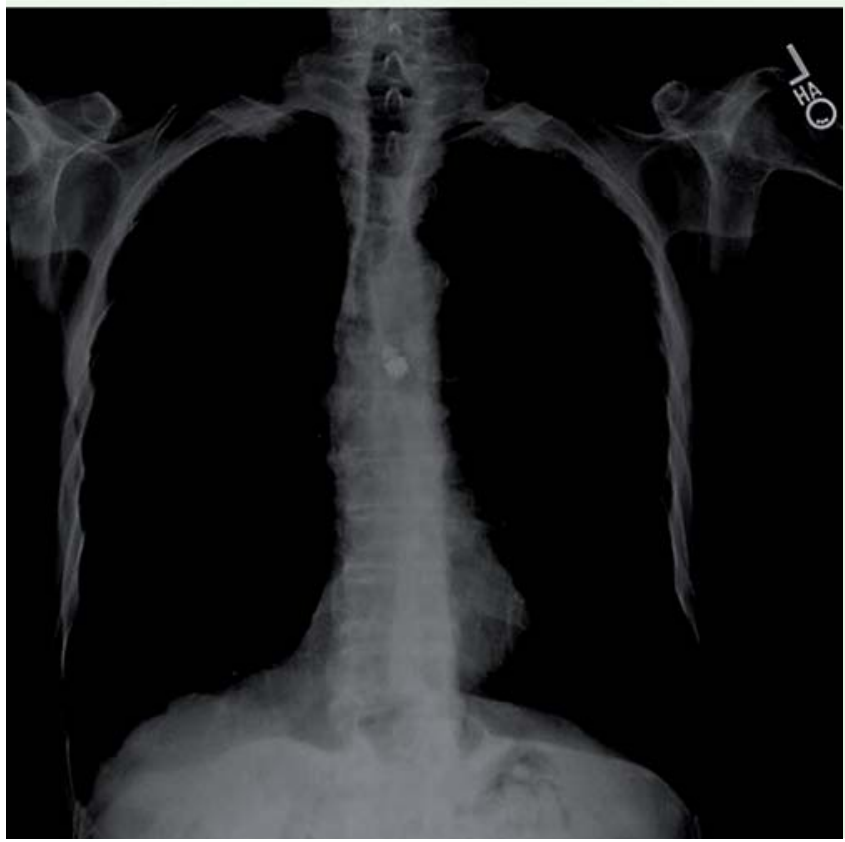

bronchial aspiration of a capsule endoscope [1-15].

Patients who aspirate this device are generally elderly and may have risk factors for aspiration. Aspiration should be suspected if cough occurs when the patient is swallowing the capsule. Aspiration can be confirmed by chest radiography or by immediate downloading of the recorded images. Fortunately, most patients are able to cough up the capsule endoscope and swallow it without intervention and do so in a short time frame. However, an invasive intervention may be required to remove the aspirated capsule from the bronchial tree. The technique employed to retrieve the device depends on the expertise of the local physicians and equip- 
ment availability ( $\bullet$ Table 1 ). Interestingly, a capsule endoscope can remain in the bronchial tree for an extended time period without significant complication to the patient.

We present a case where the capsule endoscope remained in the bronchial tree of an 81-year-old man for 110 days without serious consequences. He manifested the aspiration with a cough only at the initial swallowing of the device. Other than his age he had no risk factor for aspiration. The initial interpretation of the capsule video recording was that the capsule had remained in his esophagus for the 8 hours of recording. However, when the capsule endoscope was identified on chest radiographs ( $\bullet$ Fig. 1 ) and the video recording was reviewed, it was determined that the images had been misinterpreted. Not surprisingly, the images actually demonstrated that the device had remained in the patient's bronchus for the entire recording. The capsule was successfully retrieved from his left main stem bronchus ( $\bullet$ Fig. 2 ) using a flexible fiberoptic bronchoscope and a snare wire loop.

Endoscopy_UCTN_Code_CPL_1AI_2AB

\section{Competing interests: None}

Mahmoud Amarna', Amanda Vanlandingham², Parag Brahmbhatt', Thomas M. Roy ${ }^{1,2,3}$, Ryland P. Byrd ${ }^{1,2,3}$

${ }^{1}$ Division of Pulmonary Diseases and Critical Care Medicine, East Tennessee State University, Johnson City, Tennessee, United States

2 Department of Internal Medicine, The James H. Quillen VAMC, Mountain Home, Tennessee, United States

${ }^{3}$ Department of Pulmonary Diseases and Critical Care, The James H. Quillen VAMC, Mountain Home, Tennessee, United States

\section{References}

1 Sepehr A, Albers GC, Armstrong WB. Aspiration of a capsule endoscope and description of a unique retrieval technique. Otolaryngology 2007; 137: 965 - 966

2 Nathan S, Biernat L. Aspiration - an important complication of small-bowel video capsule endoscopy. Endoscopy 2007; 39: E343

3 Tabib S, Fuller C, Daniels J et al. Asymptomatic aspiration of a capsule endoscope. Gastrointest Endosc 2004; 60: 845-848

4 Depriest K, Wahla A, Blair R et al. Capsule endoscopy removal through flexible bronchoscopy. Respiration 2010; 79: 421 - 424

5 Lucendo A, González-Castillo S, FernándezFuente $M$ et al. Tracheal aspiration of a capsule endoscope: a new case report and literature compilation of an increasingly reported complication. Dig Dis Sci 2011; 56: $2758-2762$

6 Parker C, Davison C, Panter S. Tracheal aspiration of a capsule endoscope: not always a benign event. Dig Dis Sci 2012; 57: $1727-$ 1728

7 Pezzoli A, Fusetti N, Carella A et al. Asymptomatic bronchial aspiration and prolonged retention of a capsule endoscope: a case report. J Med Case Rep 2011; 5: 341

8 Guy T, Jouneau S, D'Halluin P et al. Asymptomatic bronchial aspiration of a video cap- sule. Interact Cardiovasc Thorac Surg 2009; 8: $568-570$

9 Choi H, Kim J, Kim H et al. A case of asymptomatic aspiration of a capsule endoscope with a successful resolution. Gut Liver 2010; 4: 114-116

10 Schneider A, Hoepffner $N$, Rösch $W$ et al. Aspiration of an M2A capsule. Endoscopy 2003; 35: 713

11 Girdhar A, Usman F, Bajwa A. Aspiration of capsule endoscope and successful bronchoscopic extraction. J Bronchology Interv Pulmonol 2012; 19: 328 - 331

12 Shiff AD, Leighton JA, Heigh RI et al. Pulmonary aspiration of capsule endoscope. Am J Gastroenterol 2007; 102: 215-216

13 Bredenoord AJ. Unintentional video capsule bronchoscopy. Eur J Gastroenterol Hepatol 2009; 21: 593-594

14 Sinn I, Neef B, Andus T. Aspiration of a capsule endoscope. Gastrointest Endosc 2004; 59: $926-927$

15 Leeds J, Chew TS, Sidhu R et al. Asymptomatic bronchial aspiration and retention of a capsule endoscope. Gastrointest Endosc 2009; 69: 561

\section{Bibliography}

DOI http://dx.doi.org/ 10.1055/s-0034-1377543

Endoscopy 2015; 47: E6-E7

(c) Georg Thieme Verlag KG

Stuttgart · New York

ISSN 0013-726X

\section{Corresponding author}

Ryland P. Byrd, Jr., MD

Veterans Affairs Medical Center 111-B

Division of Pulmonary Diseases

and Critical Care Medicine

PO Box 4000

Mountain Home

TN 37684-4000

USA

Fax: +1-423-979-3471

Ryland.Byrd@med.va.gov 